\title{
A Unified Analysis of Indicative and Biscuit Conditionals as Topics
}

\author{
Christian Ebert \\ University of Bielefeld
}

\author{
Cornelia Endriss \\ University of Osnabrück
}

\author{
Stefan Hinterwimmer \\ Humboldt-University Berlin
}

\section{Introduction}

We show syntactic and semantic similarities of two types of conditionals with fronted antecedents (normal indicative conditionals and biscuit conditionals) and two types of left dislocation constructions in German (german left dislocation and hanging topic left dislocation), which mark two types of topicality (aboutness topicality and frame setting topicality). On basis of these similarities we argue that (the antecedent if-clauses of) ICs and BCs are aboutness topics and frame setting topics, respectively.

Concerning our analysis, we first extend the approach to abountess topicality of Endriss (to appear) to frame setting topics to derive the semantic and pragmatic contribution for the left dislocation constructions. Then we apply it to the analysis of indicative conditionals of Schlenker (2004) and show how it accounts for both types of conditionals. We thus propose one uniform approach to the interpretation of topicality that accounts for the left dislocation constructions as well as the two types of conditionals.

\section{Conditionals, Left Dislocation, and Topicality}

\subsection{Two Types of Conditionals}

Consider the sentences in (1) and (2), which exemplify normal indicative conditionals (ICs) and biscuit conditionals (BCs), respectively ${ }^{1}$.

(1) If Peter went shopping, then there is pizza in the fridge.

(2) If you are hungry, (*then) there is pizza in the fridge.

Crucially, in (1) the truth of the consequent depends on the truth of the antecedent: while it is neither asserted that there is pizza in the fridge, nor that Peter went

We would like to thank Michael Franke, Philippe Schlenker, and the audience at the SALT XVIII for helpful comments on the issues of this paper. The work of the first and the third author was carried out as part of the SFB 673 Alignment in Communication and the SFB 632 Information Structure, respectively.

${ }^{1}$ Although we are, strictly speaking, dealing with pizza conditionals in this paper, the name biscuit conditional, derived from the edible substance (Austin 1961) used in his seminal example of this type of conditional, has become fairly standard. 
shopping, what is asserted is that there is a connection between Peter's shopping and there being pizza in the fridge: it cannot be the case that Peter went shopping and there is no pizza in the fridge.

In (2), in contrast, the consequent is asserted independently of the truth of the antecedent. The speaker commits himself to the truth of there being pizza in the fridge, whether the addressee is hungry or not. Note that then is prohibited for the $\mathrm{BC}$ reading of (2) - if it is present it turns into an IC (with a quite implausible meaning). Furthermore the antecedent gives conditions stating when the consequent is relevant (hence the also used term relevance conditional for BCs). In the case of 2 , for example, it is understood that the speaker assumes the assertion that pizza is in the fridge to be relevant to the listener only in case s/he is hungry.

According to traditional analyses, ICs have the truth conditions of material implication where A is the antecedent and B the consequent. This, however, has the undesirable consequence that every conditional where either A is false or B is true is automatically true, which does not correspond to speakers' intuitions. Therefore, a popular view nowadays ${ }^{2}$ treats a conditional with antecedent $\mathrm{A}$ and consequent $\mathrm{B}$ as true if in every world that differs minimally from the actual world in the respect that A is true, B is true as well (cf. Lewis 1973, Warmbrod 1983, Kratzer 1986, Nolan 2003).

BCs have been analysed as conditional assertions by DeRose and Grandy (1999): while the truth of the consequent does not depend on the truth of the antecedent, the speaker's assertion of the consequent seems to depend on the truth of the antecedent. The speaker only asserts the consequent under the condition that the antecedent is true. The problem with this account is that it is too weak. To see this, consider the examples in (3) and (4):

(3) If you don't want to watch the movie, the gardener is the killer.

(4) If the congregation is ready, I hereby declare you man and wife.

Note that no matter whether the addressee wants to watch the movie or not, the speaker spoiled it by uttering (3). Likewise, in the case of (4) the declaration of marriage happened independently of the readiness of the congregation. Hence the speech act in the consequent has actually been performed at the time of the utterance, independent of the truth of the antecedent.

Siegel (2006) analyses BCs as involving existential quantification over (presupposed relevant) potential literal acts. For instance, (2) would be analysed along the lines of the following paraphrase.

(5) If you are hungry, there exists a (presupposed relevant) assertion of 'there is pizza in the fridge'.

\footnotetext{
${ }^{2}$ At least among linguists. For philosophers of language the possible world analysis is often reserved for counterfactuals, for which it was originally developed by Lewis (1973). Indicative conditionals, in contrast, are treated as being completely different objects. They do not have truth conditions at all and their impact can roughly be described as follows (following Ramsey 1994): the speaker tells the hearer that she, upon hypothetically adding the antecedent proposition to the stock of propositions believed by her, accords the consequent proposition a high chance of being true as well, and asks the hearer to do the same thing (see (Bennett 2003) for discussion and references).
} 
Siegel (2006) argues that potential literal acts are the correct objects involved in the analysis of BCs, instead of actually performed speech acts. One of the examples she uses to show this is the following.

(6) If they ask you how old you are, you're four.

Siegel (2006) claims (6) does not behave like an imperative (7a) that could be countered by a listener with ( $7 b)$, because (7b) is not a felicitous continuation of (6).

a. A: If they ask you how old are you, (I order you to) say you're four.

b. B: No, I won't!

What this shows, however, is only that (6) provides no accessible antecedent that could license the VP ellipsis in (7b). That by (6) indeed a speech act of commanding is performed can be elucidated by a felicitous subsequent refusal to comply that is non-elliptical or one that targets a precondition of the command speech act, e.g. questioning the authority of the speaker. Indeed, (8) and (9) are fine as a reply to (6).

(8) No, I won't say that!

(9) No, I'm grown up, you can't boss me around!

This also explains why (6) does not entail that the listener is four - after all, it is a command and not an assertion, as mistakenly assumed by (Siegel 2006: p.177). The following example from (Siegel 2006: p.180, ex. (22)) illustrates the same point.

(10) If you want to hear a big fat lie, George W. and Condi Rice are secretly married.

She notes that the fact that (10) is judged true by speakers, even though the antecedent is (assumed) true and the consequent is false 'would be hard to explain within theories that maintain that speaker of BCs are asserting only the overt consequent.'. Here Siegel is again mistaken about the involved speech act. For sure, it cannot be a run-of-the-mill assertion since it has been explicitly classified as a lie beforehand. Hence the speaker is neither representing herself as knowing the content of the assertion nor does she commit herself to defend the truth of the embedded proposition as she would have according to standard views regarding the norm of assertion. Whatever the exact speech act analysis of an obvious lie involves, (6) and (10) do not provide counter-arguments to an analysis where BCs involve the performance of a speech act corresponding to the consequent. In fact, our approach will work exactly along these lines. We aim for a unified theory of ICs and BCs that accounts for the (in)dependence of the truth of antecedent and consequent in the two cases as well as for the observed relevance effects. We argue that these semantic and pragmatic effects are parallel to those exhibited by two different types of topicality. In the following we will therefore take a closer look at two left dislocation constructions that mark these two types of topicality and discuss their parallels to the two types of conditionals afterwards. 


\subsection{Two Types of Topic Constructions}

Consider the examples in (11) and (12), which exemplify german left dislocation (GLD) and hanging topic left dislocation (HTLD), respectively ${ }^{3}$.

Den Pfarrer, den kann keiner leiden.

The-ACC pastor RP-ACC can nobody like.

'The pastor nobody likes.'

Der/den Pfarrer, keiner kann ihn leiden.

The-NOM/-ACC pastor nobody can him like.

'The pastor, nobody likes him.'

We will focus on these German constructions in the following as their semantic and pragmatic differences have been worked out in detail by Frey (2004). He shows (building on Altmann 1981) that the following characteristics concerning prosodic integration $(\mathrm{P})$, the resumptive element $(\mathrm{R})$, and binding facts $(\mathrm{B})$ set these two constructions apart:

(P) In case of HTLD, the left peripheral phrase is separated from the rest of the sentence by a short pause. In the case of GLD, there usually is no such pause.

(R) GLD requires the presence of a resumptive pronoun which must be a weak d-pronoun (der, den, die, das, etc.). It is preferably realized in the prefield (i.e. in Spec., CP) of the matrix clause. The left peripheral element has to be in the same case as the resumptive pronoun.

In the case of HTLD, the resumptive element may occur in the form of a personal pronoun (cf. 12), a weak d-pronoun, a strong pronoun like dieser, an epithet or a definite description. It can show up either in the prefield or in the middlefield of the clause (cf. 12). The left peripheral element may either be in the nominative (cf. 12) or in the same case as the resumptive element.

(B) GLD allows for binding of a pronoun contained within the left peripheral constituent by a quantifier in the matrix clause. In the case of HTLD, no such binding is possible.

The following pair illustrates this contrast:

(13) Seinen $_{i}$ Vater, den verehrt jeder . $_{\text {. }}$ His-ACC father RP-ACC admires everybody.

'Everybody admires his father.'

${ }^{*}$ Sein(en $)_{i}$ Vater, jeder ${ }_{i} \quad$ verehrt ihn. His(-ACC) father everybody admires him.

\footnotetext{
${ }^{3}$ In the gloss, RP stands for 'resumptive pronoun'. Note that the English counterparts illustrated by the glosses are - quite confusingly - called topicalization and left dislocation, respectively (cf. Prince 1998).
} 
While the pronoun seinen (his) occurring in the left peripheral element can be bound by jeder (every) from within the clause in the case of the GLD construction in (13), this is not possible for the HTLD construction in (14).

Note that the HTLD construction imposes much fewer constraints on the relation of the left periphery and the matrix clause and hence the connection between the two is much looser than in the case of GLD constructions (which is also indicated by the prosodic separation).

Concerning semantic and pragmatic effects, Frey (2004) argues that GLD marks aboutness topicality in the sense of Reinhart (1981). In this view (which is based on Strawson 1964) topicality establishes the entity the sentence is about. Reinhart elaborates this idea in suggesting that the sentence topic should serve as an address at which the remaining information of the sentence, the comment, is stored.

Frey (2004) elucidates the aboutness topic-marking effect of GLD by observing that a sentence exhibiting GLD such as (15b) is an appropriate answer to an explicit request for information such as (15a) about the entity denoted by the left peripheral phrase. A sentence exhibiting a GLD construction marking a different entity as aboutness topic yields an incoherent answer in the same context (cf. 15c) despite that fact that it conveys the same information.

a. What about the pastor?

b. Der Pastor, der hat den Bürgermeister geohrfeigt. The-NOM pastor RP-NOM has the-ACC mayor slapped.

'The mayor has slapped the pastor.'

c. \#Den Bürgermeister, den hat der Pastor geohrfeigt. The-ACC mayor RP-ACC has the-NOM pastor slapped.

'The mayor has slapped the pastor.'

In contrast, HTLD indicates frame setting topicality. A frame setting topic establishes a frame of interpretation for which the following material is relevant. In this respect, HTLD is an instance of more general frame setting constructions where a conventionalized expression (e.g. as for $X, \ldots$ or concerning/regarding $X, \ldots$ ) is used to indicate that the fact expressed in the clause is relevant w.r.t. questions regarding X. The following sentence illustrates this.

(16) As for the pastor, the marriage sermon was wonderful.

Here the pastor is introduced as the frame of interpretation for which the information that the marriage sermon was wonderful is considered relevant.

Note that in these more general frame setting constructions such as (16) the left peripheral constituent is not necessarily picked up by a proform within the matrix clause. Hence, these general frame setting construction impose yet fewer syntactic constraints than HTLD on the relation of the left peripheral element and the clause.

To sum up, the difference concerning the connection of the left periphery and the clause in case of GLD vs. HTLD and more general frame setting constructions is reflected by their semantic-pragmatic function: while aboutness topicality 
(marked by GLD) signals that the clause provides direct information about the left peripheral entity, frame setting topicality (marked by HTLD etc.) only signals that the information of the clause is relevant w.r.t. some question regarding the left peripheral entity. Before we turn to our formal analyses of these intuitions, we argue that exactly the same differences can be observed with normal indicative vs. biscuit conditionals.

\subsection{Conditionals and Topicality}

It has often been observed that there is a strong syntactic similarity between ICs (and subjunctive conditionals) and correlative constructions, which 'involve a free relative clause adjoined to the matrix clause and co-indexed with a proform inside it' (Bhatt and Pancheva 2001). Bittner (2001), for instance, cites the following example from Warlpiri ${ }^{4}$, which she credits to Hale (1976).

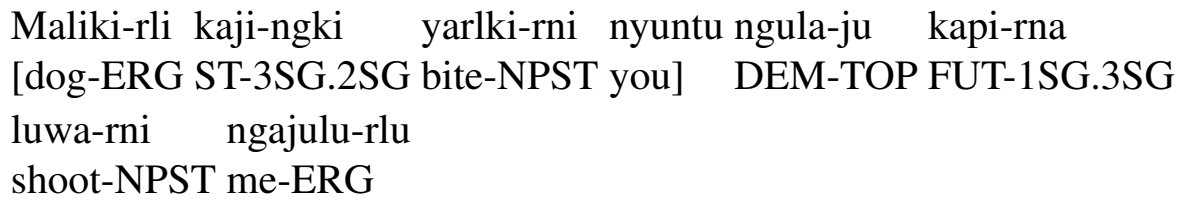

a. 'As for the dog that bites you, I'll shoot it.'

b. 'If a dog bites you, then I'll shoot it.'

As she notes, (17) introduces a topical referent via the dependent clause at the left periphery and is ambiguous between two readings. In (17a), the dependent clause refers to an individual while in (17b) it refers to a 'prominent possibility'. The correlated proform in the matrix is the topic-oriented anaphoric demonstrative ngula-ju.

Bittner's example illustrates nicely the parallels we are after: if-clauses resemble correlative constructions, which in turn introduce some type of topic. Bittner suggests that both readings of (17) should essentially have the same representation, up to logical type, and develops a formal approach along these lines. Our approach is in the same spirit with regards to this unification.

A closer look at our data allows us to detect more fine-grained parallels between the two discussed types of conditionals (ICs vs. BCs) and the two discussed types of left dislocation constructions (GLD vs. HTLD). The following characteristics separate ICs from BCs.

(P) In the case of BCs, the left peripheral if-clause is separated from the rest of the sentence by a short pause. In the case of ICs with left peripheral if-causes, in contrast, there is no such pause.

(R) then can be regarded as a proform which relates back to the possibilities introduced by the if-clause (cf. Iatridou 1994, Izvorski 1996). Crucially, BCs do not allow for the presence of then, while ICs do.

\footnotetext{
${ }^{4}$ In the glosses, the non-obvious abbreviations are as follows: $\mathrm{ST}=$ same topic, $\mathrm{TOP}=$ topic, NPST $=$ non-past
} 
(B) While binding into the if-clause is possible in the case of ICs, it is not in the case of BCs as the following example illustrates (see also Haegeman 2003):

(18) Wenn man $\operatorname{sie}_{i}$ gut pflegt, dann blüht [jede Orchidee $]_{i}$ if one it well groom then blossoms every orchid mehrmals im Jahr. several times in the year

'Every orchid blossoms several times a year, if you groom it well.'

*Wenn Du etwas über $\operatorname{sie}_{i}$ wissen willst, [jede Orchidee] ${ }_{i}$ if you something about it to know want every orchid blüht mehrmals im Jahr. blossoms several times in the year

Comparing these characteristics to those separating GLD and HTLD from the previous section it is evident that ICs and BCs strongly resemble GLD and HTLD (and more general frame setting constructions), respectively ${ }^{5}$. Given the topic-marking function of GLD and HTLD, we conclude that the left peripheral if-clauses of ICs and BCs constitute instances of aboutness topicality and frame setting topicality, respectively. In both cases the if-clause serves as the topic, while the matrix clause supplies the comment (cf. Haiman 1978, Bittner 2001). Indeed, it is easily possible to find equivalent frame setting paraphrases for BCs:

(20) If you are hungry, there is pizza in the fridge.

(21) As for the possibility that you are hungry, there is pizza in the fridge.

In this example the semantic and pragmatic effects are completely parallel: the antecedent/frame setting topic establishes the conditions for the relevance of the matrix speech act and the proposition expressed by the matrix clause is asserted unconditionally.

In the following section we first derive the semantic and pragmatic contributions of GLD and HTLD by extending the approach to aboutness topics by Endriss (to appear) to frame setting topics. We then apply the same analysis to the approach for indicative conditionals of Schlenker (2004), who treats if-clauses as definite descriptions of possible worlds. This eventually accounts for the semantic and pragmatic effects of ICs and BCs.

\section{A Unified Analysis}

\subsection{Topics as Speech Acts}

Endriss (to appear) argues that aboutness topics should be interpreted via a separate speech act of topic establishment $\mathrm{REF}_{X}$ resembling an act of referring Searle

\footnotetext{
${ }^{5}$ In (Ebert et al. to appear) we discuss this resemblance in greater detail.
} 
(1969) or frame setting (Jacobs 1984, Lambrecht 1994). This act formally establishes a new aboutness topic by introducing a novel discourse referent $X$ for the topic-marked constituent. The remainder of the sentence (i.e. the comment) is then interpreted as a predicate inside the originating speech act to which this discourse referent $X$ is supplied as an argument. This is in fact an implementation of the storage address metapher of Reinhart (1981): the information of the comment is 'stored' at the 'address' $X$.

Crucially, the $\operatorname{REF}_{X}$ act is performed before this originating act. In the following we will restrict ourselves to assertions for the sake of a simple exposition. In this case, an assertion of a proposition structured into topic and comment is interpreted as indicated in the schema in (22).

$$
\operatorname{ASSERT}(\text { comment }(\text { topic })) \leadsto \operatorname{REF}_{X}(\text { topic }) \& \operatorname{ASSERT}(\operatorname{comment}(X))
$$

The $\mathrm{REF}_{X}$ act establishes the topic by introduction of a novel discourse referent $X$ followed by a subsequent speech act of asserting that the comment holds of $X$. The two speech acts are conjoined via speech act conjunction \&.

This approach is reminiscent of the two steps in categorical judgements introduced by the philosopher Franz Brentano. A categorical judgement is performed by 'the act of recognition of that which is to be made the subject [i.e. the topic in our terminology], and the other, the act of affirming or denying what is expressed by the predicate about the subject' (Kuroda 1972: p.154). Such a judgement corresponds straightforwardly to what a sentence with a topic expresses.

Concerning the derivation of the predicate that corresponds to the comment, Endriss and Hinterwimmer (to appear) assume that the d-pronoun in the specifier of the matrix-CP is interpreted like a relative pronoun, i.e. that it triggers lambdaabstraction. In a GLD sentence such as (11), repeated here as (23a), the matrix clause is thus interpreted as in (23b), while the entire sentence is interpreted as in (23c):

a. Den Pfarrer, den kann keiner leiden. The-ACC pastor RP-ACC can nobody like.

'The pastor nobody likes.'

b. $\llbracket$ den kann keiner leiden $\rrbracket=\lambda y \cdot \neg \exists z[\operatorname{human}(z) \wedge \operatorname{like}(z, y)]$

c. $\operatorname{REF}_{X}($ lx $[$ pastor $(x)]) \& \operatorname{ASSERT}(\neg \exists z[\operatorname{human}(z) \wedge \operatorname{like}(z, X)])$

In uttering (23a), the speaker first introduces the pastor as a topic in a separate speech act. Subsequently, he asserts that nobody likes the just introduced pastor.

Note that in this case the topical constituent is a definite description referring to an individual of semantic type $e$. Therefore the discourse referent $X$ in the REF act can straightforwardly refer to this individual. In fact, we do not observe any truth conditional difference between the assertion in (23c) and the following plain assertion where topicality is ignored ${ }^{6}$.

\footnotetext{
${ }^{6}$ But we do predict a pragmatic difference. In (23c), the REF act of topic introduction may fail in its own right, for instance if the corresponding individual does not exist. We take this to be a fact towards an explanation of the often discussed observation that non-referring definite descriptions
} 


$$
\operatorname{ASSERT}(\neg \exists z[\operatorname{human}(z) \wedge \operatorname{like}(z, l x[\text { pastor }(x)])])
$$

This is different if the topical constituent is an indefinite of generalized quantifier (GQ) type $\langle\langle e, t\rangle, t\rangle$ as in (25).
a. Einen
Song von Bob Dylan, den
kennt jeder.
Some-ACC song of Bob Dylan, RP-ACC knows everybody.
'Everybody knows some song of Bob Dylan.'
b. $\operatorname{REF}_{X}(\exists x[$ song_of $B D(x)]) \& \operatorname{ASSERT}(\forall y[\operatorname{human}(y) \rightarrow$ know $(y, X)]$

In this case a suitable representative of the GQ has to be created to which the topic discourse referent in the REF act can refer. Endriss (to appear) argues that a minimal witness set of the topical GQ is such a suitable representative (cf. also Szabolcsi 1997). With this analysis, a truth conditional effect of topic marking is predicted: the topic takes widest (possibly island-free) scope. In (25), for instance, the speaker introduces some song of Bob Dylan as topic with a subsequent assertion that everybody knows this just introduced song. We refer the reader to (Endriss to appear) for further details.

Now that we sketched an analysis of aboutness topicality, let us turn to frame setting topicality. The crucial difference here lies in the treatment of the proform. Recall that general frame setting constructions do not require the presence of any proform in the matrix clause (cf. 16, repeated as 26a). If we want to adapt the mechanism laid out above to this case, we cannot derive a predicate from the matrix$\mathrm{CP}$ due to the absence of a proform that may trigger lambda-abstraction. Hence, the matrix-CP is interpreted as a stand-alone proposition (26b).
a. As for the pastor, the marriage sermon was wonderful.
b. $\llbracket$ the marriage sermon was wonderful $\rrbracket=\operatorname{wonderful}($ marriage sermon)
c. $\operatorname{REF}_{X}($ lx $[$ pastor $(x)]) \&$ ASSERT(wonderful(marriage_sermon))

The final representation in (26c) hence tells us that in uttering (26a) the speaker introduces the pastor as the topic and asserts that the marriage sermon was wonderful.

At this point it is crucial to note that the only connection between the topic and the comment lies in the consecutive performance of the corresponding speech acts. Here the issue of relevance comes into play: using standard Gricean assumptions, an assertion is only felicitous if it is relevant to the preceding discourse (i.e. the assertion must serve to at least partially answer the question under discussion). In case of (26c) this means that the assertion that the marriage sermon was wonderful must be relevant to the preceding act of introducing the pastor as topic (i.e. must at least partially answer the question under discussion raised by the preceding REF act, e.g. something like What about the pastor?) in order to be felicitous. In other words, the speaker implicates that this proposition is relevant concerning (questions regarding) the pastor. This relevance implicature is exactly the pragmatic effect we observe in the case of frame setting constructions.

produce some kind of squeamish feeling in a listener if they are topical while they do not if they are non-topical (see e.g. Strawson 1964, von Fintel 2004). In future work we will work out the precise felicity conditions of the REF act. 
In the case of HTLD constructions as (12, repeated as 27a), we proceed analogously since we view them as a special case of frame setting constructions. More precisely, we again view the matrix-CP as an independent proposition. Therefore we treat any present proform not as triggering lambda-abstraction as in the GLD case, but as anaphoric element. For (27a) this analysis hence yields (27b) for the interpretation of the matrix- $\mathrm{CP}$ and eventually (27c) as the final representation.

$$
\begin{aligned}
& \text { a. Der/den Pfarrer, keiner kann ihn leiden. } \\
& \text { The-NOM/-ACC pastor nobody can him like. } \\
& \text { 'The pastor nobody likes.' } \\
& \text { b. } \llbracket \text { den kann keiner leiden } \rrbracket=\neg \exists z[\operatorname{human}(z) \wedge \operatorname{like}(z, y)] \\
& \text { c. } \operatorname{REF}_{X}(\text { lx }[\text { pastor }(x)]) \& \operatorname{ASSERT}(\neg \exists z[\operatorname{human}(z) \wedge \operatorname{like}(z, y)])
\end{aligned}
$$

Here the proform ihn (him) ends up as a free variable $y$ that must be resolved to some salient individual in the context. Since the immediately preceding context consists of the introduction of the pastor via the REF act, this individual is highly salient and therefore the most likely antecedent for the resolution. And again, we get the implicature that states that the assertion is relevant w.r.t. the introduction of topic.

To sum up, we see topicality as introducing a separate speech act of topic establishment prior to the original speech act of the utterance. In the case of aboutness topicality (instantiated by GLD) the relation of topic and comment is one of predication: a required proform ensures that the comment is interpreted as a predicate that is applied to (the discourse referent referring to) the topic. In case of frame setting topicality (instantiated by HTLD and more general frame setting constructions) the comment is interpreted as an independent proposition. The cohesion between the REF speech act of topic introduction and the original speech act of the utterance is ensured by general conversational principles, most prominently relevance.

While the corresponding relevance implicature may clearly be felt in examples like (26), it is important to note that in the case of aboutness topicality the relevance condition is trivially fulfilled, because of the predicative relation of topic and comment: obviously, the assertion that a predicate holds of an argument is relevant w.r.t. (questions regarding) the argument.

In the following section, we will straightforwardly apply this analysis of topicality to conditionals.

\section{2. if-clauses as Topics}

We follow Schlenker (2004), who builds on Stalnaker (1968), in analysing the antecedents of normal indicative conditionals as definite descriptions of possible worlds. In this approach an if-clause if $\varphi$ is interpreted as the unique possible world which is most similar to the actual world $w_{0}$ among all possible worlds where $\varphi$ is true. The if-clause in (1, repeated as 28a) thus denotes the object in (28b): the unique world which is most similar to the actual world among all posible worlds 
where Peter went shopping ${ }^{7}$. The proposition denoted by the consequent is then evaluated w.r.t. the denotation of the if-clause, i.e. it is checked whether the consequent proposition is true in the world selected by the if-clause. As our analysis works on the level of speech acts we assume that hence (28c) is actually asserted with the utterance of the conditional ${ }^{8}$.

a. If Peter went shopping, then there is pizza in the fridge.

b. 【if Peter went shopping $\rrbracket=\boldsymbol{l}_{w_{0}} w[$ go_shopping $(w)($ peter $)]$

c. ASSERT(pizza_in_fridge $\left(\boldsymbol{l}_{w_{0}} w[\right.$ go_shopping $(w)($ peter $\left.\left.)]\right)\right)$

Based on our observations concerning the parallels between ICs and GLD construction from the preceding section we assume that the if-clause in (28a) is actually interpreted as an aboutness topic. Therefore, according to our analysis, a REF act of topic establishment introduces a discourse referent $X$ for the unique world denoted by the if-clause, and it is then asserted that the predicate of worlds denoted by the consequent holds of $X$.

As mentioned in the preceding section, then can be argued to be a proform of possible worlds (cf. e.g. Iatridou 1994, Izvorski 1996, Bhatt and Pancheva 2001). We assume it to trigger lambda-abstraction over possible worlds in exactly the same way in which d-pronouns like der trigger lambda-abstraction over individuals in the case of GLD. Hence we derive a predicate over possible worlds, i.e. a proposition, for the consequent of the conditional (29a) to which the topic discourse referent is supplied in the final representation (29b).

$$
\begin{aligned}
& \text { a. } \llbracket \text { then there is pizza in the fridge } \rrbracket=\lambda w . p i z z a \_i n \_f r i d g e(w) \\
& \text { b. } \operatorname{REF}_{X}\left(\boldsymbol{l}_{w_{0}} w[\text { go_shopping }(w)(\text { peter })]\right) \& \operatorname{ASSERT}(\text { pizza_in_fridge }(X))
\end{aligned}
$$

The speaker first introduces the possible world in which Peter went shopping (and which is most similar to the actual world among those worlds where this is true) and then he asserts that pizza is in the fridge in this world. This is precisely the normal indicative conditional meaning we get with Schlenker's analysis (28c). Again we do not see any semantic effect of the topical status of the if-clause, similar to the individual case in (23c) vs. (24). Furthermore, the condition that the assertion be relevant w.r.t. the context, i.e. (question regarding) the topic, is trivially fulfilled due to the fact that the asserted proposition is a predication of the topic.

As for BCs, recall that they do not allow the proform then in their consequent. Therefore, as in the individual case of frame setting (26), the topical discourse referent is not supplied as an argument for the proposition corresponding to the consequent. Instead, the proposition is again treated as independent, i.e. as being asserted as holding in the actual world. (30b) illustrates the result for the BC in $(2$, repeated as $30 \mathrm{a})$

\footnotetext{
${ }^{7}$ The subscript at the iota-operator $l$ indicates the world of evaluation w.r.t. which 'similarity' is measured. We ignore the issue of plurality necessary for cases of quantification over possible worlds here (cf. Schlenker 2004).

${ }^{8}$ We grossly simplify all formal representations by ignoring the internal structure of the clauses in order to get our main points across.
} 
a. If you are hungry, there is pizza in the fridge.

b. $\operatorname{REF}_{X}\left(\boldsymbol{l}_{w_{0}} w[\right.$ hungry $(w)($ listener $\left.)]\right) \& \operatorname{ASSERT}\left(\right.$ pizza_in_fridge $\left.\left(w_{0}\right)\right)$

Here the speaker introduces the possible world in which the listener is hungry as topic and then he asserts that there is pizza in the fridge in the actual world. And again, due to the relevance requirement the speaker implicates that this fact is relevant w.r.t. the possibility that the listener is hungry. This is precisely what we observe for BCs: the consequent is asserted unconditionally as being true in the actual world, while the antecedent serves as a means to make it relevant - if the assertion had been relevant to the context without uttering the antecedent, then the speaker would not have gone through the trouble of doing so. Furthermore, this analysis explains the restrictions on the occurrence of then. In fact, if then is inserted into the consequent of a BC it turns into an IC as in the following variant of (30a).

(31) If you are hungry, then there is pizza in the fridge.

This is exactly what we would predict, since in this case the consequent clause would be analysed as a predicate, yielding as assertion that there is pizza in the fridge in the possible world where the listener is hungry (that is most similar to the actual world among all worlds where this is true). As often in cases of BCs turning into ICs, such an analysis yields a quite implausible meaning.

\section{Binding}

Having presented our basic analysis of ICs vs. BCs we now turn to an explanation of the binding facts. Recall that binding into the dislocated element is possible in the case of GLD and ICs, but impossible in the case of HTLDs and BCs.

We start again with the case of GLD and aboutness topicality and proceed along the lines of (Ebert and Endriss 2007). There we argued that cases like (13, repeated as 32) exemplify functional topics. In these cases, the speaker introduces a function as the entitiy the sentence is about (the function being-father-of in the following example).

Seinen $_{i}$ Vater, den verehrt jeder .

His-ACC father RP-ACC admires everybody.

'Everybody admires his father.'

Hence the correct analysis must treat the left dislocated phrase as a function that is introduced as the aboutness topic of the sentence via the REF act. Informally speaking, it should yield a representation that states that the speaker introduces a function of being-father-of as the topic with a subsequent assertion that everybody admires whoever is assigned to him by this function.

We further argued in (Ebert and Endriss 2007) that dislocated constituents with bound pronouns do not take narrow scope w.r.t. the binding matrix quantifier (as one may assume at first glance) but functional wide scope, which can be 
truth-conditionally distinguished from genuine narrow scope in case of dislocated quantificational phrases. If the analysis proceeds along the informal paraphrase above, this scope behaviour is ensured. In (Ebert and Endriss 2007) we presented a formal analysis along these lines that we will review and extend in the following.

In case of (32) the dislocated definite denotes a function of type $\langle e, e\rangle$. The denotation of seinen Vater (his father) in (33a) takes an individual $y$ and returns the individual that satisfies the father_of $(y)$ predicate. The resumptive d-pronoun correspondingly is of the same functional type $\langle e, e\rangle$ and combines with the matrix verb, which is type-shifted by application of Jacobson's Z-operator (Jacobson 1999) to facilitate its combination with a functional element $(33 \mathrm{~b}, \mathrm{c})$ :

$$
\begin{aligned}
& \text { a. } \llbracket \text { seinen Vater } \rrbracket=\lambda y . l x[\text { father_of }(y)(x)] \\
& \text { b. } Z=\lambda R_{\langle\langle e, e\rangle, t\rangle} \lambda f_{\langle e, e\rangle} \lambda x_{e} \cdot R(f(x))(x) \\
& \text { c. } \llbracket \text { den verehrt jeder }=\lambda f_{\langle e, e\rangle} \cdot \forall y[\operatorname{human}(y) \rightarrow Z(\text { admire })(f)(y)] \\
& =\lambda f_{\langle e, e\rangle} \cdot \forall y[\operatorname{human}(y) \rightarrow \operatorname{admire}(y, f(y))]
\end{aligned}
$$

Given this derivation of the left peripheral topical constituent and the comment matrix-CP, the same interpretation principle as in the non-functional case applies. The topic is introduced in a separate REF speech act via a novel discourse referent, followed by an assertion of the matrix-CP predicate applied to the topical discourse referent - only that this time the topic and the corresponding discourse referent are of functional type. The result is as follows.

$$
\operatorname{REF}_{f}(\lambda y . l x[\text { father_of }(x, y)]) \& \operatorname{ASSERT}(\forall y[\operatorname{human}(y) \rightarrow \operatorname{admire}(y, f(y))])
$$

Here the speaker introduces the being-father-of function as the entity the sentence is about and asserts that everybody admires the individual that is assigned to him by this function.

We can extend this analysis of functional aboutness topicality straightforwardly to cases of frame setting topicality as in the non-functional case above. Again the only difference to the aboutness case is the interpretation of the proform (if present) in the matrix-CP comment. As in the non-functional case, any proform is treated not as triggering lambda-abstraction but as anaphoric element. Therefore, the matrix-CP of the HTLD example in (14, repeated here as 35a) is again interpreted as an independent proposition (35b).
a. $*$ Sein $(\text { en })_{i}$ Vater, jeder ${ }_{i} \quad$ verehrt ihn. His(-ACC) father everybody admires him.
b. 【jeder verehrt ihn $\rrbracket=\forall y[\operatorname{human}(y) \rightarrow \operatorname{admire}(y, z)]$
c. $\operatorname{REF}_{f}(\lambda y . l x[$ father_of $(x, y)]) \& \operatorname{ASSERT}(\forall y[\operatorname{human}(y) \rightarrow \operatorname{admire}(y, z)])$

The resulting interpretation in (35c) can thus be paraphrased as follows: first, the function from individuals into their fathers is established as the topic and then it is asserted that everybody admires some salient individual. Since it is hard to find a context where this is coherent, (35a) is odd.

As in the non-functional case, the analyses for ICs and BCs run entirely parallel. As the dislocated if-clause contains a pronoun it denotes a function from 
individuals into worlds, i.e. it is of type $\langle e, s\rangle$. dann (then) again denotes a corresponding variable triggering lambda-abstraction and combines with the matrix verb that is type-shifted via an adapted version $Z^{\prime}$ of Jacobson's $Z$. Again this results in a predicate to which the topic function is supplied as argument. For the IC in (18, repeated as 36a) the derivation of the if-clause and the consequent clause is shown in (36c) and (36d), respectively.

a. Wenn man $\operatorname{sie}_{i}$ gut pflegt, dann blüht [jede Orchidee $]_{i}$ if one it well groom then blossoms every orchid mehrmals im Jahr. several times in the year

'Every orchid blossoms several times a year, if you groom it well.'

b. $Z^{\prime}=\lambda R_{\langle\langle s, e\rangle, t\rangle} \lambda f_{\langle e, s\rangle} \lambda x_{e} R(f(x))(x)$

c. 【wenn man sie gut pflegt $\rrbracket=\lambda x . l_{w_{0}} w[$ well_groomed $(w)(x)]$

d. 【dann blüht jede Orchidee mehrmals im Jahr $=\lambda f_{\langle e, s\rangle} \cdot \forall y\left[\operatorname{orchid}(y) \rightarrow Z^{\prime}(\right.$ blossom_several_times_in_year $\left.)(f)(y)\right]$ $=\lambda f_{\langle e, s\rangle} \cdot \forall y[\operatorname{orchid}(y) \rightarrow$ blossom_several_times_in_year $(f(y))(y)]$

e. $\operatorname{REF}_{f}\left(\lambda x . l_{w_{0}} w[\right.$ well_groomed $\left.(w)(x)]\right)$

$\&$ ASSERT $(\forall y[\operatorname{orchid}(y) \rightarrow$ blossom_several_times_in_year $(f(y))(y)])$

The final representation (36e) shows the topic introduction of a function in the REF speech act that assigns to each individual the unique world where it is well groomed which is most similar to the actual world among all those worlds where this is true. It is then asserted that for every orchid it is true in the world assigned to it by this function that it blossoms several times in a year. This is exactly as desired.

In the case of BCs such as (19, repeated as 37a) the matrix clause does not denote a predicate but a stand-alone proposition that is interpreted w.r.t. the actual world by default.

a. $*$ Wenn Du etwas über $\operatorname{sie}_{i}$ wissen willst, [jede Orchidee $]_{i}$ if you something about it to know want every orchid blüht mehrmals im Jahr. blossoms several times in the year

b. $\operatorname{REF}_{X}\left(\lambda x . l_{w_{0}} w[\right.$ want_to_know_sth_about $(w)($ listener,$\left.x)]\right)$ $\& \operatorname{ASSERT}\left(\forall y\left[\operatorname{orchid}(y) \rightarrow\right.\right.$ blossom_several_times_in_year $\left.\left.\left(w_{0}\right)(y)\right]\right)$

(37a) can thus only be interpreted in the following way (cf. 37b): the speaker establishes a function from individuals into the world where the listener wants to know something about that individual which is most similar to the actual world ...) and subsequently asserts that every vase is valuable in the actual world. As it is difficult to think of a context where the latter proposition would be relevant w.r.t. the former function, the sentence as a whole is odd. 


\section{Further Issues}

In this section we briefly discuss some further issues that we left out of the discussion so far.

\section{1. if-clauses without then}

In ICs the proform then is not obligatory, as illustrated in the following example.

(38) If Axel prepares a meal, the kitchen is a mess.

Given the prominent role we assign to the analysis of the proform an obvious question is how ICs without then are dealt with. We tentatively suggest that in these cases the if-clause is not left-dislocated but still part of the matrix clause, and hence not marked as aboutness topic. Consequently, it would not be interpreted as topic in a separate REF speech act, but as part of the matrix clause along the lines of a standard conditional analysis as in (28) that is truth conditionally equivalent to the topic analysis in (29). These two variants of ICs (with/without then) would then be treated entirely parallel to the distinction of GLD (signalling aboutness topic marking) vs. simple fronting of the corresponding phrase (no topic marking). We hence predict that the presence of then indicates a normal indicative conditional reading, while the absence does not allow any conclusion as to whether the conditional is an IC or a $\mathrm{BC}^{9}$.

\subsection{Right Peripheral if-clauses}

if-clauses quite naturally also occur at the right periphery of the consequent clause for both ICs and BCs as the following variations of (1) and (2) exemplify.

(39) There is pizza in the fridge, if Peter went shopping.

(40) There is pizza in the fridge, if you are hungry.

Interestingly, there is a pair of right peripheral constructions that seems to pattern with GLD and HTLD, respectively, namely German Right Dislocation (GRD) and afterthought $(A T)$. In both constructions an NP follows the right edge of a clause that contains a coreferent proform. (41) illustrates GRD, while (42) illustrates AT (slightly modified from Averintseva-Klisch 2006).

(41) Ich mag sie ${ }_{i}$ nicht, die Serena ${ }_{i}$.

I like her not the Serena

(42) Und dann passierte es $e_{i}$, dieser schreckliche Autounfall.

And then happened it, this terrible traffic accident

\footnotetext{
${ }^{9}$ For further discussion on the meaning and occurrence restrictions of then see (Iatridou 1994, Izvorski 1996). E.g. Iatridou (1994) argues that then triggers a presupposition that effectively bars it from occurring with asserted consequents and consequently with biscuit conditionals. Unfortunately, we have no space to discuss her analysis any further in this paper.
} 
Averintseva-Klisch (2006) investigates syntactic and semantic differences of these two constructions and notes among others that

(P) ' $[\mathrm{G}] \mathrm{RD}$ is prosodically integrated into its host sentence [...], whereas AT builds a prosodic unit (optionally divided by a pause from the clause) [...] of its own' (Averintseva-Klisch 2006: 16)

(R) 'Strict morphological agreement (in case, gender and number) between the clause-internal proform and the NP is obligatory for [G]RD and optional for AT' (Averintseva-Klisch 2006: 17)

While it is obvious that $(\mathrm{P})$ and $(\mathrm{R})$ pattern with the corresponding points of the characteristics of the left dislocation constructions (thus hinting at a parallel of GLD and GRD as well as HTLD and AT), there are also differences. For instance, Averintseva-Klisch (2006) points out that for GRD the right peripheral element may not be quantificational (comprising indefinite NPs such as two women). However, indefinites NPs are licensed in left peripheral position in GLD (cf. Frey 2004, Endriss to appear).

Concerning a semantic and pragmatic analysis Averintseva-Klisch (2006) suggests that GRD 'mark[s] the introduction of the NP as the discourse topic referent for the following discourse segment' (p. 23) and that AT has the function of resolving an unclear pronominal reference in the clause. While it seems that her GRD analysis can be reconciled with our analysis of GLD and ICs in principle (thus providing an analysis of right peripheral ICs like 39), it is not so clear how her proposal for AT could be reconciled with our analysis of HTLD and how it could lead to an analysis of (40). The precise syntactic parallels and differences of right peripheral if-clauses and right dislocation constructions as well as a unified explanation of their semantic and pragmatic contribution will be subject of further work.

\subsection{Other Consequent Speech Acts}

So far, we restricted our attention to assertive consequence speech acts, but our approach is designed to work with other speech acts in the same way. For instance, (6), (43), and (44) could be analysed as a REF speech act followed by a command, a question, and a request, respectively.

(43) If John is so smart, why can't he find a job?

(44) If you see John, please say hello from me.

Further work is needed to work out the details of such analyses, in particular the precise preconditions and effects of the REF act in combination with its subsequent act and the restriction that is responsible for the cohesion of the two. 


\section{References}

Altmann, Hans: 1981, Formen der Herausstellung im Deutschen. Niemeyer, Tübingen.

Austin, J. L.: 1961, 'Ifs and Cans', in Philosophical Papers, 153-180. Oxford University Press, Oxford.

Averintseva-Klisch, Maria: 2006, 'The 'Separate Performative' Account of the German Right Dislocation', in C. Ebert and C. Endriss (eds.), Proceedings of Sinn und Bedeutung 10 (ZASPiL 44), 15-28. Berlin.

Bennett, Jonathan: 2003, A Philosophical Guide to Conditionals. Clarendon Press, Oxford.

Bhatt, R. and R. Pancheva: 2001, 'Conditionals', in M. Everaert and H. van Riemsdijk (eds.), The Blackwell Companion to Syntax, Vol. I, 638-687. Blackwell.

Bittner, Maria: 2001, 'Topical Referents for Individuals and Possibilities', in R. H. et al (ed.), Proceedings from SALT XI, 36-55.

DeRose, Keith and Richard E. Grandy: 1999, 'Conditional Assertions and 'Biscuit' Conditionals', Noûs 33, 405-420.

Ebert, Christian and Cornelia Endriss: 2007, 'Functional Topics', in E. PuigWaldmüller (ed.), Proceedings of the Sinn und Bedeutung XI, 194-208.

Ebert, Christian, Cornelia Endriss, and Stefan Hinterwimmer: to appear, 'Topics as Speech Acts - An Analysis of Conditionals', in Proceedings of the WCCFL XXVII.

Endriss, Cornelia: to appear, Quantificational Topics. A Scopal Treatment of Exceptional Wide Scope Phenomena, Studies in Linguistics and Philosophy. Springer.

Endriss, Cornelia and Stefan Hinterwimmer: to appear, 'Indefinites as Direct and Indirect Aboutness Topics', in C. Féry and M. Zimmermann (eds.), Information Structure. Oxford University Press.

von Fintel, Kai: 2004, ‘A Minimal Theory of Adverbial Quantification', in H. Kamp and B. Partee (eds.), Context-Dependence in the Analysis of Linguistic Meaning, 137-175. Elsevier Ltd, Oxford.

Frey, Werner: 2004, 'Notes on the Syntax and the Pragmatics of German Left Dislocation', in H. Lohnstein and S. Trissler (eds.), The Syntax and Semantics of the Left Periphery, 203-233. Mouton de Gruyter.

Haegeman, Liliane: 2003, 'Conditional Clauses: External and Internal Syntax', Mind \& Language 18(4), 317-339.

Haiman, John: 1978, 'Conditionals are Topics', Language 54, 565-589.

Hale, Ken: 1976, 'The Adjoined Relative Clause in Australia', in R. Dixon (ed.), Grammatical Categories in Australian Languages, 78-105. Australian Institute of Aboriginal Studies, Canberra.

Iatridou, Sabine: 1994, 'On the Contribution of Conditional Then', Natural Language Semantics 2, 171-199.

Izvorski, Roumyana: 1996, 'The Syntax and Semantic of Correlative Proforms', in K. Kusumo (ed.), Proceedings of NELS 26, 133-147. Harvard University 
and MIT.

Jacobs, Joachim: 1984, 'Funktionale Satzperspektive und Illokutionssemantik', Linguistische Berichte 91, 25-58.

Jacobson, Pauline: 1999, 'Towards a Variable-Free Semantics', Linguistics \& Philosophy 22, 117-184.

Kratzer, Angelika: 1986, 'Conditionals', Chicago Linguistics Society 22, 1-15.

Kuroda, Shige-Yuki: 1972, 'The Categorical and the Thetic Judgement: Evidence from Japanese Syntax', Foundations of Language 9, 153-185.

Lambrecht, Knud: 1994, Information Structure and Sentence Form. Cambridge University Press, Cambridge, Massachusetts.

Lewis, David: 1973, 'Counterfactuals and Comparative Possibility', Journal of Philosophical Logic 2, 418-446.

Nolan, Daniel: 2003, 'Defending a Possible-Worlds Account of Indicative Conditionals', Philosophical Studies 116, 215-269.

Prince, Ellen F.: 1998, 'On the Limits of Syntax, with Reference to Left-Dislocation and Topicalization', in P. W. Culicover and L. McNally (eds.), The Limits of Syntax (Syntax and Semantics 29), 281-302. Academic Press, New York.

Ramsey, Frank: 1994, 'General Propositions and Causality', in D. Mellor (ed.), Philosophical Papers, 145-163. Cambridge University Press. orig. 1929.

Reinhart, Tanya: 1981, 'Pragmatics and Linguistics. An Analysis of Sentence Topics', Philosophica 27, 53-94.

Schlenker, Philippe: 2004, 'Conditionals as Definite Descriptions', Research in Language and Computation 2, 417-462.

Searle, John: 1969, Speech Acts: An Essay in the Philosophy of Language. Cambridge University Press, London.

Siegel, Muffy: 2006, 'Biscuit Conditionals. Quantification over Potential Literal Acts.', Linguistics \& Philosophy 29, 167-203.

Strawson, Peter: 1964, 'Identifying Reference and Truth Values', Theoria 30. reprinted in Steinberg and Jakobovits (eds.), Semantics, 1971.

Szabolcsi, Anna: 1997, 'Strategies for Scope Taking', in A. Szabolcsi (ed.), Ways of Scope Taking, 109-154. Kluwer Academic Publishers, Dordrecht.

Warmbrod, Kenneth: 1983, 'Epistemic Conditionals', Pacific Philosophical Quarterly 64, 249-265. 